\title{
Why do mothers fail to breastfeed successfully? A descriptive study done at selected lactation management centres in Sri Lanka
}

\author{
*Mekala Fernando ${ }^{1}$, Shamini Prathapan ${ }^{2}$ \\ Sri Lanka Journal of Child Health, 2017; 46(4): 337-342
}

\begin{abstract}
Background: Exclusive breastfeeding (BF) up to six months is recommended in Sri Lanka because it is known to be the best food for the infants and it provides vast benefits to the mother as well. Since exclusive BF rates decline with the advancing age of the baby, it is quite obvious that mothers face difficulties in BF.
\end{abstract}

Objective: To describe the factors associated with difficulties in BF in mothers with neonates attending selected lactation management centres in the Colombo district.

Method: A hospital based cross sectional study was conducted at lactation management centres in De Soysa Maternity Hospital and Colombo South Teaching Hospital from August to September 2015. Mothers who paid their first visit with the corresponding neonates were selected. Sample size was 288 . They were selected by systematic random sampling method, proportionate to their monthly admissions excluding neonates with congenital hypothyroidism. Study instruments used were a structured interviewer administered questionnaire, Breast Feeding Observation Form and a checklist of the neonate. Chi squared test and Fisher's exact test where relevant were used for statistical analysis.

Results: One hundred and sixty three (56.6\%) had difficulty in BF. Among the sociodemographic factors studied, being in extended family $(p=0.012)$ was significantly associated. Among the maternal factors, not receiving antenatal health education after getting admitted to the ward $(p=0.03)$, having pain $(p=0.016)$ and discomfort $(p=0.01)$ during $\mathrm{BF}$, not having previous experience in $\mathrm{BF}(p=0.006)$ and being discharged within 24 hours after delivery $(p=0.03)$ were significantly associated after controlling for confounding factors.

${ }^{1}$ National STD/AIDs Control Programme, $\quad$ Sri Lanka, ${ }^{2}$ University of Sri Jayewardenepura, Sri Lanka

*Correspondence: meksfdo@gmail.com

(Received on 28 January 2017: Accepted after revision on 17 March 2017)

The authors declare that there are no conflicts of interest

Personal funding was used for the project.

Open Access Article published under the Creative

Commons Attribution CC-BY (c) (i)
Conclusions: Being in an extended family, not receiving antenatal health education, having pain and discomfort during $\mathrm{BF}$, not having previous experience in $\mathrm{BF}$ and being discharged within 24 hours after delivery were significantly associated with BF difficulties in mothers with neonates attending selected lactation management centres in the Colombo district.

DOI: http://dx.doi.org/10.4038/sljch.v46i4.8381

(Key words: Breastfeeding difficulty, maternal factors, neonatal factors)

\section{Introduction}

Exclusive breastfeeding (BF) is defined as the infant receiving only breast milk, including breast milk that has been expressed or from a wet nurse and nothing else, except for oral rehydration solution, medicines, vitamins and minerals ${ }^{1}$. Exclusive BF alone can reduce neonatal infection by about $22 \%{ }^{2}$. A study in the United States found a $25 \%$ increase in mortality among non-breast fed infants ${ }^{3}$. A study in Sri Lanka showed about $16 \%$ incidence of breast and nipple abnormalities in primigravida women and around $92 \%$ of them exclusively breast fed with support ${ }^{4}$. A study in a rural area in Sri Lanka found that $32 \%$ of the babies less than 3 months of age were on formula milk, and that difficulty in BF was a significant factor in starting formula feeding ${ }^{5}$.

Around $94 \%$ of mothers with BF difficulties thought that they had inadequate milk while $18 \%$ thought nutrients in breast milk were inadequate ${ }^{6}$. Sixty percent of mothers were practising inappropriate attachment and positioning in $\mathrm{Nepal}^{7}$. It has been found that higher maternal and paternal level of education, gestational age more than 37 weeks and mothers with previous experience in BF are factors positively associated with exclusive BF whereas low family income, low maternal age, primiparity and mothers returning to work contribute to interruption of $\mathrm{BF}^{8}$.

According to Infant and Young Child Feeding Programme Review: Case Study Sri Lanka 2009, the challenges to improve BF rates were identified as traditional practices that interfered with good feeding practices such as giving coriander water and discarding colostrum, complaints by mothers of insufficient breast milk and perceptions that if a baby cried, mother did not have breast milk, problems with attachment and positioning, widespread availability of infant formula and 
promotion of its use, including by grandmothers, bottle feeding of young infants, limited lactation management skills among health providers as well as inadequate monitoring and supervision, hospital practices not conducive to the establishment of good $\mathrm{BF}$ practices and unsupportive workplace environments for BF women?. A community based study done in Northwestern Pennsylvania revealed that the decision to breastfeed or bottle feed was made during pregnancy or during the first trimester. Main reasons for mothers to choose bottle feeding was mother's perception of father's attitude, uncertainty regarding the quantity of breast milk and return to work ${ }^{10}$.

Thus, it is evident that difficulty in BF is a problem in Sri Lanka and in the world although exclusive BF is being addressed in abundance. This is evident with the decline in rates of exclusive $\mathrm{BF}$ with advancement of baby's age. Effective methods to educate the mothers regarding correct BF practices should be brought forward. As a guide to bring out the necessary changes to improve the $\mathrm{BF}$, and counselling programmes, it is important to find the factors which contributed to difficulty in BF so that necessary measures can be taken to overcome those problems. Thus, grass root level health care workers can be educated regarding those factors so that they can be identified and necessary measures taken at their level if possible, without directing them to the lactation management centres (LMCs).

\section{Method}

A descriptive cross sectional study was done in LMCs at De Soysa Maternity hospital (DMH) and Colombo South Teaching Hospital (CSTH) both of which are located in Colombo, the commercial capital of Sri Lanka. This study was carried out from April 2015 to January 2016. Mothers and neonates attending those LMCs as their first visit following recent delivery, were taken as the study sample. Mothers with neonates attending LMCs at DMH and CSTH irrespective of the place of delivery were included in the study and neonates who were diagnosed to have chronic medical problems such as congenital hypothyroidism were excluded because they can interfere with sucking.

The sample size was 294; with an expected proportion of postnatal mothers having BF difficulty as $50 \%$; alpha error was $5 \%$, precision $6 \%$ and nonresponse rate $10 \%$. Systematic random sampling technique was used with a skip interval of three. Therefore, every fourth eligible mother-neonate pair attending LMCs at DMH and CSTH, 242 and 52 respectively, were selected as study units, proportionate to the monthly admissions of each LMC.

A structured pretested interviewer administered questionnaire, BF Observation Tool, which was adopted from B-R-E-A-S-T-Feeding observation form by H. C. Armstrong, training guide in lactation management, New York, IFAN and UNICEF 1992 which was adopted by Family Health Bureau, were the study instruments used in the study ${ }^{11}$. Breastfeeding observation form included five areas viz. body position, responses, emotional bonding, anatomy and suckling. Each area has several subcomponents. Each subcomponent is given a score, one if there is a BF difficulty section or zero, if there is no BF difficulty section. A BF score was given by adding all the scores in each subcomponent with a range of maximum value of 22 and minimum value of 0 . A score of 12 or below was categorized as having BF difficulty while a score of 13 or above was categorized as no BF difficulty as used in previous studies.

Inter observer reliability was assured by the use of the same wordings in the questionnaire and training of the other investigators on the way of asking questions and observation of BF thus minimizing information bias. Selection of the study units were done in the chronological order as they entered the LMC and every other mother-neonate pair who were eligible for the study were recruited by a person who was not aware of the objectives of the study and who was not involved in data collection after being informed about the inclusion and exclusion criteria, ensuring minimal selection bias.

Data was collected on all days of the week during open hours to ensure that mothers belonging to different categories (e.g. working mothers) are included in the study sample. As the data were collected at the LMC, privacy was ensured and information bias was minimized. To exclude bias which can occur due to observation, the investigators spent about half an hour, helping nurses in routine work at the LMC, for the feeling to be faded off from the participants' minds that they are being observed.

Ethical clearance was obtained from Ethics Review Committee of the Postgraduate Institute of Medicine, Colombo. Institutional clearance was obtained from $\mathrm{DMH}$ and $\mathrm{CSTH}$ prior to commencement of the study. Permission was taken from the relevant consultant neonatologists, Deputy Director of DMH and from the Director of CSTH. Nursing Officers in-charge were well informed about the study. Data were collected by the principal investigator and another data collector with similar working experience. Mothers were interviewed and observed inside the LMC itself after the spending some time there before starting data collection thus minimizing observational bias.

Frequency distribution of these factors were cross analysed against the BF status using Chi squared test (and Fisher's test where relevant). A level of 0.05 was used to determine significance. All variables at bivariate level with a $p$ value of less than 0.2 were 
eligible for multivariate logistic regression analysis. Analysis was performed using purposeful selection. Results

The study included 288 participants with a response rate of $98 \%$. The frequency distribution of the mothers' BF status is shown in Table 1.

\section{Table 1}

Frequency distribution of mothers' BF status

\begin{tabular}{|l|c|}
\hline Breastfeeding status (BF) & Frequency (\%) \\
\hline Difficult & $163(56.6)$ \\
\hline Not difficult & $125(43.4)$ \\
\hline Total & $288(100.0)$ \\
\hline
\end{tabular}

Mothers without BF difficulty came to the LMCs because they were informed regarding the particular service by the ward staff where they delivered the baby and they were asked to visit to the LMC when they came to the well-baby clinic, to ensure correct BF technique.
Among mothers who had difficulty in BF, 60 $(36.8 \%)$ had passed GCE ordinary level and among those who did not have difficulty in BF 55 (44\%) had the same educational level. There were 97 (59.5\%) mothers, aged between 20 and 35 years, among the mothers who had difficulty in BF and 77 (60.8\%) mothers aged between 20 and 35 years, among the mothers who did not have difficulty in BF. Among mothers who had difficulty in BF 100 $(61.3 \%)$ were Sinhalese and $38(23.3 \%)$ were Tamils. There were $90(55.2 \%)$ Buddhist mothers who had difficulty in BF. There were 73 (44.8\%) mothers who had a monthly family income between Rs 21,000-30,000 and 15 (9.2\%) mothers with an income more than Rs 51,000 had BF difficulty. Among the mothers who had difficulty in BF, 49 $(30.2 \%)$ were employed while $113(69.8 \%)$ were unemployed. Maternal factors causing BF difficulty are shown in Table 2. Neonatal factors causing BF difficulty are shown in Table 3.

Table 2: Maternal factors causing breastfeeding (BF) difficulty

\begin{tabular}{|c|c|c|c|}
\hline \multirow[t]{2}{*}{ Maternal factor } & \multicolumn{2}{|c|}{ BF difficulty } & \multirow[t]{2}{*}{ Significance } \\
\hline & $\begin{array}{l}\text { Present } \\
\text { No. }(\%)\end{array}$ & $\begin{array}{c}\text { Absent } \\
\text { No. (\%) }\end{array}$ & \\
\hline $\begin{array}{l}\text { Previous experience in breast surgeries } \\
\text { Present } \\
\text { Absent }\end{array}$ & $\begin{array}{c}24(14.7) \\
139(85.3)\end{array}$ & $\begin{array}{c}06(04.8) \\
119(95.2)\end{array}$ & $\begin{array}{l}X^{2}=7.47 ; \mathrm{df}=01 \\
p=0.006 \\
\mathrm{OR}=3.42(1.35-8.66)\end{array}$ \\
\hline $\begin{array}{l}\text { Number of children } \\
\text { Primiparity } \\
\text { Multiparity }\end{array}$ & $\begin{array}{c}120(73.6) \\
43(26.4)\end{array}$ & $\begin{array}{l}49(39.2) \\
76(60.8)\end{array}$ & $\begin{array}{l}X^{2}=34.57 ; \mathrm{df}=01 \\
p<0.0001 \\
\text { OR }=4.33(2.62-7.14)\end{array}$ \\
\hline $\begin{array}{l}\text { Mode of delivery } \\
\text { Normal vaginal delivery } \\
\text { Instrumental delivery / caesarean section }\end{array}$ & $\begin{array}{l}95(58.3) \\
68(41.7) \\
\end{array}$ & $\begin{array}{l}92(73.6) \\
33(26.4) \\
\end{array}$ & $\begin{array}{l}X^{2}=7.29 ; \mathrm{df}=01 \\
p=0.007 \\
\mathrm{OR}=0.50(0.30-0.83)\end{array}$ \\
\hline $\begin{array}{l}\text { Type of anaesthesia } \\
\text { General } \\
\text { Spinal }\end{array}$ & $\begin{array}{c}00(0.0) \\
45(100)\end{array}$ & $\begin{array}{l}01(03.7) \\
26(96.3)\end{array}$ & $p=0.38$ \\
\hline $\begin{array}{l}\text { Availability of bed and /or chair in postnatal ward } \\
\text { Yes } \\
\text { No (Sharing of beds) }\end{array}$ & $\begin{array}{c}130(79.8) \\
33(20.2) \\
\end{array}$ & $\begin{array}{c}108(86.4) \\
17(13.6) \\
\end{array}$ & $\begin{array}{l}X^{2}=2.18 ; \mathrm{df}=01 \\
p=0.014 \\
\mathrm{OR}=0.62(0.33-1.17)\end{array}$ \\
\hline $\begin{array}{l}\text { Encouragement regarding } B F \text { in ward } \\
\text { Yes } \\
\text { No }\end{array}$ & $\begin{array}{c}143(87.7) \\
20(12.3)\end{array}$ & $\begin{array}{c}125(100) \\
00(0.0)\end{array}$ & $\begin{array}{l}X^{2}=16.48 ; \mathrm{df}=01 \\
p<0.0001\end{array}$ \\
\hline $\begin{array}{l}\text { Observation and correction of BF technique in ward } \\
\text { Present } \\
\text { Absent }\end{array}$ & $\begin{array}{c}119(83.2) \\
24(16.8) \\
\end{array}$ & $\begin{array}{c}122(97.6) \\
03(02.4)\end{array}$ & $\begin{array}{l}X^{2}=15.23 ; \mathrm{df}=01 \\
p<0.0001 \\
\mathrm{OR}=.12(0.04-0.42)\end{array}$ \\
\hline $\begin{array}{l}\text { Antenatal health education } \\
\text { Received } \\
\text { Not received }\end{array}$ & $\begin{array}{c}144(88.3) \\
19(11.7)\end{array}$ & $\begin{array}{c}121(96.8) \\
04(03.2)\end{array}$ & $\begin{array}{l}X^{2}=6.88 ; \mathrm{df}=01 \\
p=0.009 \\
\mathrm{OR}=0.25(0.08-0.76)\end{array}$ \\
\hline $\begin{array}{l}\text { Place of antenatal health education } \\
\text { Field antenatal health clinic } \\
\text { Yes } \\
\text { No } \\
\text { Hospital antenatal clinic } \\
\text { Yes } \\
\text { No } \\
\text { Ward } \\
\text { Yes } \\
\text { No }\end{array}$ & $\begin{array}{c}107(65.6) \\
56(34.4) \\
19(11.8) \\
142(88.2)\end{array}$ & $\begin{array}{c}106(84.8) \\
19(15.2) \\
31(25.2) \\
92(74.8)\end{array}$ & $\begin{array}{l}X^{2}=1.51 ; \mathrm{df}=01 \\
p=0.22 \\
\mathrm{OR}=0.61(0.37-1.26) \\
X^{2}=13.48 ; \mathrm{df}=01 \\
p<0.0001 \\
\mathrm{OR}=0.34(0.19-0.62) \\
X^{2}=8.63 ; \mathrm{df}=01 \\
p=0.003 \\
\mathrm{OR}=0.3(0.21-0.74)\end{array}$ \\
\hline
\end{tabular}


Table 3: Neonatal factors causing breastfeeding difficulty

\begin{tabular}{|c|c|c|c|}
\hline \multirow[t]{2}{*}{ Neonatal factors } & \multicolumn{2}{|c|}{ Breastfeeding difficulty } & \multirow[t]{2}{*}{ Significance } \\
\hline & $\begin{array}{c}\text { Present } \\
\text { Frequency }(\%)\end{array}$ & $\begin{array}{c}\text { Absent } \\
\text { Frequency }(\%)\end{array}$ & \\
\hline $\begin{array}{l}\text { Birth weight } \\
<2500 \mathrm{~g} \text { and }>3500 \mathrm{~g} \\
2500 \mathrm{~g}-3500 \mathrm{~g}\end{array}$ & $\begin{array}{c}53(32.5) \\
110(67.5) \\
\end{array}$ & $\begin{array}{l}35(28.0) \\
90(72.0)\end{array}$ & $\begin{array}{l}X^{2}=.68 ; \mathrm{df}=01 \\
p=0.41 \\
\mathrm{OR}=1.24(0.74-2.06)\end{array}$ \\
\hline $\begin{array}{l}\text { Period of amenorrhoea at birth } \\
<37 \text { weeks } \\
\geq 37 \mathrm{weeks} \\
\end{array}$ & $\begin{array}{c}30(18.5) \\
132(81.5) \\
\end{array}$ & $\begin{array}{c}18(14.4) \\
107(85.6) \\
\end{array}$ & $\begin{array}{l}X^{2}=0.86 ; \mathrm{df}=01 \\
p=0.35 \\
\mathrm{OR}=1.35(0.74-2.56)\end{array}$ \\
\hline $\begin{array}{l}\text { Admission to premature baby uni } \\
\text { /special care baby unit } \\
\text { Yes } \\
\text { No }\end{array}$ & $\begin{array}{l}03(50.0) \\
03(50.0)\end{array}$ & $\begin{array}{c}02(50.0) \\
02(50.0\end{array}$ & $p=1.00$ \\
\hline
\end{tabular}

None of the neonatal factors looked for in the study viz. birth weight, period of amenorrhea at birth, and admission to premature baby unit / special care baby unit, were statistically significant.
The results of the multivariate analysis are shown in Table 4.

Table 4: Multivariate analysis results

\begin{tabular}{|c|c|c|c|c|}
\hline \multirow[t]{2}{*}{ Factor } & \multirow[t]{2}{*}{ Significance } & \multirow[t]{2}{*}{$\operatorname{Exp}(B)$} & \multicolumn{2}{|c|}{ 95\% CI for $\operatorname{Exp}(B)$} \\
\hline & & & Lower & Upper \\
\hline Employment status & 0.94 & 0.97 & 0.44 & 2.14 \\
\hline Extended family type & 0.012 & 0.42 & 0.21 & 0.82 \\
\hline Illness of mother & 0.11 & 0.43 & 0.15 & 1.24 \\
\hline Perceived inadequacy of milk supply & 0.64 & 1.26 & 0.48 & 3.27 \\
\hline Pain during breast feeding & 0.08 & 0.52 & 2.4 & 1.1 \\
\hline Stress during breast feeding period & 0.016 & 0.18 & 0.04 & 0.73 \\
\hline Discomfort during breast feeding & 0.01 & 0.17 & 0.04 & 0.65 \\
\hline Undergone breast surgeries earlier & 0.7 & 0.8 & 0.25 & 2.5 \\
\hline Receiving antenatal (AN) health education & 0.53 & 1.58 & 0.36 & 6.8 \\
\hline Receiving AN health education at hospital AN clinic & 0.07 & 2.09 & 0.92 & 4.76 \\
\hline Receiving AN health education after admission to ward & 0.03 & 2.53 & 1.05 & 6.08 \\
\hline Having more than one child & 0.79 & 0.91 & 0.47 & 1.78 \\
\hline Previous experience in breast feeding & 0.006 & 0.2 & 0.06 & 0.63 \\
\hline Mode of delivery & 0.19 & 0.78 & 0.54 & 1.13 \\
\hline Availability of bed and chair & 0.76 & 1.14 & 0.46 & 2.8 \\
\hline Discharge from the ward within 24 hours & 0.03 & 0.07 & 0.006 & 0.84 \\
\hline
\end{tabular}

Living in an extended family $(p=0.012)$, being stressed while $\mathrm{BF}(p=0.016)$, feeling discomfort during $\mathrm{BF}(p=0.01)$, not receiving antenatal health education regarding $\mathrm{BF}$ after getting admitted to the ward ( $p=0.03)$, not having previous experience on $\mathrm{BF}(p=0.006)$ and being discharged from the ward within 24 hours $(p=0.03)$ were significantly associated with BF difficulty after controlling for confounding factors.

\section{Discussion}

Over $55 \%$ of the mothers who presented to LMCs had difficulties in BF. Of the socio-economic factors, being unemployed and belonging to extended families were significantly associated with $\mathrm{BF}$ difficulties whereas maternal educational level, maternal age and monthly family income were not significantly associated. Whilst all postnatal experiences of the mother studied including facilities and services provided at the postnatal ward were significantly associated in univariate analysis, only receipt of antenatal health education was significantly associated in multivariate analysis.

Though the educational level and age of the mother were not significantly associated with $\mathrm{BF}$ difficulties in this study, a community based study showed a statistically significant association in mothers in the urban area, when comparing their age and educational level with the introduction of formula milk ${ }^{12}$. The difference in the two studies could be due to the different study settings used. Educational level and age of the mother were also statistically significantly associated in a study done in Korea ${ }^{13}$. The possible reason for the difference of the results could be that Korea is a country with suboptimal levels of exclusive BF. In our study, employment status and type of family were significantly associated with BF difficulty in contrast to the findings in a community based 
study $^{14}$. The possible reason could be that our study was done in a hospital setting and not in the community setting.

In our study, primiparity was significantly associated with BF difficulties $(\mathrm{p}<0.0001)$. This is similar to a hospital study done in India ${ }^{15}$. Undergoing instrumental delivery or caesarean section was significantly associated with BF status as evidenced by a meta-analysis which revealed that babies born by lower segment caesarean section were more likely to be fed with infant formula within the first three days ${ }^{16}$. The possible reason for the association of BF difficulty with undergoing instrumental delivery or lower segment caesarean section may be the post procedural pain. Non availability of a bed and/or a chair in the postnatal ward implied that the mother had inadequate rest during hospital stay. Being discharged within 24 hours after the delivery which is contradictory to the guidelines on post-partum care and early newborn care is also associated with BF difficulty. These two facts could have occurred due to overcrowding.

Although the majority of mothers were encouraged regarding $\mathrm{BF}$, there was a statistically significant difference between those who were encouraged and not encouraged among those with BF difficulty. Among those who were encouraged there was a significant association between those who were observed and corrected and not. Hospital antenatal clinic and the antenatal ward were shown to be the places for health education which will have better impact on BF. Similarly, a hospital based study done in India revealed that antenatal visits and BF advice received during the antenatal period were significantly associated with exclusive $\mathrm{BF}^{8}$.

Mother's overall knowledge was not associated with the BF status. It could be due to contamination bias. Incorrect feeding practices like feeding formula milk or anything other than breast milk and bottle feeding were shown to be significantly associated which must have been due to the poor knowledge on the importance of exclusive $\mathrm{BF}$ and the adverse outcomes of formula or other feeds which also showed significant association with difficulties in BF in this study. Two community based study showed similar results ${ }^{14,17}$.

Birth asphyxia and the baby being admitted to the special care baby unit were not associated with BF status. The possible reason could be that the babies who were given care were paid greater attention and their BF status must have been established before discharge. Neonatal birth weight less than $2500 \mathrm{~g}$ or more than $3500 \mathrm{~g}$ and the period of amenorrhoea less than 37 weeks were also not associated with $\mathrm{BF}$ status which could also be due to the fact that some of the extreme premature and extreme low birth weight babies are admitted to the SCBU. A Danish study also revealed that $68 \%$ of premature babies exclusively breast fed on discharge ${ }^{17}$.

This study was done as a hospital based study due to feasibility issues as data was collected during one month period which composed of an interviewer administered questionnaire, observation of BF and exanimation of the neonate in order to fill the Breast Feeding Observation Form and the check list of the neonate which were time consuming. The study setting being limited to two centers in Colombo district was a limitation in this study. Video recording of $\mathrm{BF}$ would have been helpful to overcome observational bias in this study.

\section{Conclusions}

Being in an extended family, not receiving antenatal health education, having pain and discomfort during $\mathrm{BF}$, not having previous experience in $\mathrm{BF}$ and being discharged within 24 hours after delivery were significantly associated with BF difficulties in in mothers with neonates attending selected lactation management centres in the Colombo district.

\section{References}

1. World Health Organisation. Global Nutrition Targets 2025: Breastfeeding policy brief. Available from:

http://www.who.int/nutrition/publications/ globaltargets2025_policybrief_breastfeedi ng/en/

2. World Health Organisation. Global strategy for infant and young child feeding. WHO Geneva 2003. Available from: http://www.who.int/nutrition/publications/ gs_infant_feeding_text_eng.pdf

3. Quigley MA, Kelly YJ, Sacker A. Breastfeeding and hospitalization for diarrhoeal and respiratory infection in the United Kingdom Millennium Cohort Study. Pediatrics 2007; 119(4):e837-42. https://doi.org/10.1542/peds.2006-2256 PMid: 17403827

4. Amarasena S. Incidence of breast and nipple abnormalities among primigravida women in Sri Lanka. Sri Lanka Journal of Child Health 2006; 35(2): 51-4

5. Wijekoon AS, Thattil RO, Schensul SL. First trimester feeding in a rural Sri Lankan population. Social Science and Medicine 1995; 40(4):443-9. https://doi.org/10.1016/02779536(94)0014 5-J

6. Dhammika BL, Gunawardena N. Knowledge, practices and concerns regarding exclusive breastfeeding for six 
months among mothers of infants in a suburban setting in Sri Lanka. Sri Lanka Journal of Child Health 2012; 41(1): 9-14. https://doi.org/10.4038/sljch.v41i1.4130

7. Chaudhary RN, T. Shah, and S. Raja. Knowledge and practice of mothers regarding breast feeding: a hospital based study. Health Renaissance 2011; 9(3): 194200.

https://doi.org/10.3126/hren.v9i3.5590

8. Chudasama R, Patel P, Kavishwar A. Breastfeeding initiation practice and factors affecting breastfeeding in South Gujarat region of India. The Internet Journal of Family Practice 2009; 7(2).

9. Infant and Young Child Feeding Programme Review Case Study: Sri Lanka, June 2009

10. Arora S, Mc Junkin C, Wehrer J, Kuhn P. Major factors influencing breast feeding rates: Mother's perception of father's attitude and milk supply. Pediatrics 2000; 106(5): e67

https://doi.org/10.1542/peds.106.5.e67

PMid: 11061804

11. Health Bureau. Breast feeding counselling: A Training Course, Family Health Bureau, Colombo: 1993.

12. Fernando DN, Soysa PE. Factors influencing infant feeding patterns in Sri Lanka

13. Kim MJ, Kim YM, Yoo JH. Factors affecting exclusive breast-feeding during the first 6 months in Korea. Pediatrics

International 2013; 55(2):177-80.

https://doi.org/10.1111/ped.12004

PMid: 23110585

14. Agampodi TC, Piyaseeli UK. Breastfeeding practices in a public health field practice area in Sri Lanka: a survival analysis. International Breastfeeding Journal 2007; 2(1):1.

https://doi.org/10.1186/1746-4358-2-1

PMid: 17204150 PMCid: PMC1779768

15. Narayan $\mathrm{S}$, Natarajan $\mathrm{N}$, Bawa KS. Maternal and neonatal factors adversely affecting breastfeeding in the perinatal period. Medical Journal Armed Forces India 2005; 61(3):216-9.

https://doi.org/10.1016/S03771237(05)80 156-X

16. Kuyper E, Vitta B, Dewey K. Implications of caesarean delivery for breastfeeding outcomes and strategies to support breastfeeding. Alive Thrive Tech Brief 2014; 8:1-9.

17. Maastrup R, Hansen BM, Kronborg H, Bojesen SN, Hallum K, Frandsen A, Kyhnaeb A, Svarer I, Hallström I. Factors associated with exclusive breastfeeding of preterm infants. Results from a prospective national cohort study. PloS one. 2014; 9(2): e89077.

https://doi.org/10.1371/journal.pone.0089 077

PMid: 24586513 PMCid: PMC3929624 